\title{
Crowdfunding cultural and commercial entrepreneurs: an empirical study on motivation in distinct backer communities
}

\author{
Tobias Bürger $\mathbb{D} \cdot$ Simon Kleinert $\mathbb{D}$
}

Accepted: 13 August 2020 / Published online: 13 November 2020

(C) The Author(s) 2020
Keywords Entrepreneurship · Arts · Cultural and creative industries $\cdot$ Crowdfunding $\cdot$ Backer community . Self-determination theory $\cdot$ Motivation

JEL classifications $\mathrm{G} 23 \cdot \mathrm{G} 41 \cdot \mathrm{L} 26$

\section{Introduction}

Reward crowdfunding allows entrepreneurs to tap a large number of potential backers and offer rewards such as new products or services, community activities, or thank-you letters in exchange for backers' financial contributions. Given the growing relevance of reward crowdfunding to fund cultural and commercial entrepreneurial endeavors, it is not surprising that entrepreneurs are increasingly interested in understanding how to appeal to their relevant communities of backers (Belleflamme et al. 2014; Josefy et al. 2017). Crowdfunding research has started to address this by examining the motives of backers to provide funding for campaigns, with mixed results. Some studies find that backers are extrinsically motivated to engage in reward crowdfunding and pledge to pre-order products or to collect rewards (Gerber et al. 2012; Lin et al. 2014; Cholakova and Clarysse 2015). Other studies point to latent intrinsic backer motives such as altruism, the desire to have an impact on the project success or to be part of a community (Gerber et al. 2012; André et al. 2017; Kuppuswamy and Bayus 2017; Nielsen and Binder 2020). While previous research has considerably advanced our knowledge on backer motivation, the
S. Kleinert

School of Business and Economics, Maastricht University, Tongersestraat 53, 6211 Maastricht, LM, Netherlands 
literature has not distinguished between different backer communities. Backer motivation is considered as generalizable among crowd funders, with the assumption that they are a homogenous group of individuals (Allison et al. 2015; Cholakova and Clarysse 2015).

However, backers often belong to specific crowdfunding communities, in which individuals share a common interest or cause and are attracted by similar crowdfunding campaigns (Josefy et al. 2017). The shared interest or cause in a crowdfunding community is likely to manifest itself in the different purposes that entrepreneurs pursue with their crowdfunding campaign. Therefore, it is crucial to distinguish among two common types of entrepreneurs who start reward crowdfunding campaigns: Commercial entrepreneurs who seek the creation of economic value or shareholder wealth by introducing new products or services for customers (Parhankangas and Renko 2017) and cultural entrepreneurs who identify and exploit opportunities in the cultural domain (arts, theater, music, film, etc.) and seek to establish cultural value for the general public (Dacin et al. 2010). ${ }^{1}$ Following the novel idea of Josefy et al. (2017) about backer communities of interest, it is conceivable that commercial entrepreneurs attract a community of backers distinct to backers that support cultural entrepreneurs. How different communities of commercial and cultural backers are motivated to fund crowdfunding campaigns is an open and relevant research question (Cholakova and Clarysse 2015), and this study aims to address this gap by delineating the motivational differences between these communities of backers.

To answer our research question, we build on selfdetermination theory (Deci and Ryan 1985): the dominant theoretical approach to study human motivation (Deci et al. 1999) and the motivation of backers in crowdfunding (Allison et al. 2015; Cholakova and Clarysse 2015). The theory suggests that rewards can enhance or undermine extrinsic or intrinsic motivations (Ryan and Deci 2000a). In line with the central tenets of SDT, we assess backer motivation among the two communities with a new empirical strategy; that is, we

\footnotetext{
${ }^{1}$ We follow the conceptualization of Dacin et al. (2010) and consider cultural entrepreneurship as a distinct type of entrepreneurship that is regularly used to describe entrepreneurs in the arts, and the cultural and creative sectors. Another conceptualization was put forward by Lounsbury and Glynn (2001) who use the terminology to describe the cultural dimension of storytelling in the context of establishing venture legitimacy.
}

analyze which rewards backers pledge for in cultural and commercial crowdfunding campaigns. Rewards can provide a pecuniary value such as a product or price discount, or be without any tangible compensation such as a symbolic thank-you note, or a community activity with the project creators and other backers (Thürridl and Kamleitner 2016). The baseline hypothesis of our study is that salient pecuniary rewards increase the motivation of backers to contribute to a crowdfunding project. Following explorative interviews, we expect that commercial and cultural backer communities share different values and enjoy different utilities from pledging in crowdfunding. We posit that pecuniary rewards attract commercial backers because this community resembles early-customers who pledge to receive an extrinsically motivating reward. This community pledges out of curiosity aroused by a new product (i.e., epistemic value), and the prospective utility from a product (i.e., functional value) (Sheth et al. 1991; Sweeney and Soutar 2001). On the other hand, explorative interviews point to cultural backers' need to feel related; they want to be part of the cultural community and the value creation process. This community is more concerned about the critical funding needs of cultural entrepreneurs and is motivated to pledge by the prospects of getting involved in their community (i.e., social value) and having a positive impact (i.e., emotional value) (Sheth et al. 1991). Therefore, we expect cultural backers to derive less utility from pecuniary rewards and more from intrinsically motivating rewards that address their social and emotional needs.

We test our hypotheses with observational data from Startnext, the largest reward crowdfunding platform in the German-speaking region (Crosetto and Regner 2018). With Startnext's support, we were able to create a unique dataset comprising 2334 rewards from 225 cultural and commercial projects open for funding between 2015 and 2020. The multi-level nature of the data enabled us to examine the motivation of backers to pledge for individual rewards, importantly while controlling for general heterogeneity in project quality by using random-effects models (Cameron and Trivedi 2013).

Our study makes several relevant contributions to crowdfunding and entrepreneurship research. First, our study provides fresh insights into the motivation of backers in reward crowdfunding. Previous findings provide inconclusive evidence of financial and nonfinancial backer motives (e.g., Cholakova and Clarysse 
2015; Kuppuswamy and Bayus 2017). We make use of a new empirical strategy by examining the rewards, which are the central driver of extrinsic and intrinsic motivation according to SDT (Deci et al. 1999; Ryan and Deci 2017) and demonstrate that backer motivation is generally driven by pecuniary rewards. However, our results also highlight that backers should not be treated as a homogenous group; motivation differs significantly for backers who support cultural and commercial projects.

Second, we build on and extend the few studies that investigate the role of communities in reward crowdfunding (Belleflamme et al. 2014; Josefy et al. 2017; Murray et al. 2020). Josefy et al. (2017) suggest that crowdfunding communities consist of backers who share similar interests and values. We add to this literature by demonstrating that distinct communities enjoy different utilities from backing projects and by introducing cultural backers and commercial backers as two distinct communities. A significant difference is, for instance, the desire of backers to become an active part of their community, which is more relevant for cultural than commercial backers.

Third, our study provides new insights into how cultural entrepreneurs can use crowdfunding to raise funding successfully. Entrepreneurship research frequently examines the resource mobilization practices of commercial and social entrepreneurs (Parhankangas and Renko 2017), while cultural entrepreneurs have been largely neglected as distinct type of entrepreneur (Dacin et al. 2010; Bürger and Volkmann 2020). Also, due to their unique entrepreneurial profiles and venture characteristics (Woronkowicz and Noonan 2019), cultural entrepreneurs have, for a long time, suffered disproportionally from limited access to the early-stage financing market (Konrad 2018). Our results inform cultural entrepreneurs on how they can turn their community into an asset and make use of digital means to connect with potential customers and supporters and raise funding.

\section{Theoretical framework and hypotheses}

\subsection{Literature review on motivation to participate in different crowdfunding forms}

Crowdfunding stands in contrast to traditional sources of new venture financing as funding is supplied by a crowd of individuals instead of a few, often local and profit-driven investors such as venture capitalists or angel investors (Stevenson et al. 2019). Unsurprisingly, the motivation of crowd funders to support campaigns has become of central interest in entrepreneurship research, and previous research has made considerable progress in explaining the motivation of funders in the different crowdfunding forms.

Equity crowdfunding is a crowdfunding context with similarities to traditional forms of new venture financing as investors participate in the long-term success of startup companies. Investors in equity crowdfunding are, in general, considered as small investors who have a financial return motive (Ahlers et al. 2015; Cholakova and Clarysse 2015) and base their investment decisions on objective quality signals (Kleinert et al. 2020). Recent evidence also points to heterogeneity in the group of investors in equity crowdfunding with different investor types such as casual investors, crowd enthusiasts, and sophisticated investors; however, the majority of these investors are extrinsically motivated by the prospects of a high financial return (Kleinert and Volkmann 2019; Goethner et al. 2020).

Microlending is a crowdfunding context in which microlenders provide loans predominantly for necessity entrepreneurs (Allison et al. 2015; Moss et al. 2015). Allison et al. (2015) show that the crowd is more likely to fund when entrepreneurial narratives are framed as an opportunity to help others and confirm the predominant view that the motivation of the crowd in the microlending context is highly prosocial (Galak et al. 2011).

In contrast to the unambiguous results on equity crowdfunding and microlending, there is inconclusive evidence of backers' motivation to support projects in reward crowdfunding. Preliminary evidence from Gerber et al. (2012) suggests that backers primarily seek to receive tangible products or services often before their market launch. However, the authors also discover additional motives such as help others, support creators, and causes or engaging with a creative community. Focusing on backers of technology projects, Lin et al. (2014) identify four distinct crowd funder archetypes based on a set of intrinsic and extrinsic motivations: altruism, (i.e., prosocial reasons), social benefits, (i.e., building identity and network), rewards, (i.e., extrinsic motivation), and reputation (i.e., recognition from participating in a community). While they find that there are different backer types with heterogeneous 
motivations to support technology projects, the majority of backers are driven by an extrinsic motive to receive the product. Furthermore, Belleflamme et al. (2014) suggest that compared to regular consumers, crowd funders enjoy additional "community benefits." Kuppuswamy and Bayus (2017) study the funding dynamics of reward crowdfunding projects. The authors show that backers have prosocial interests and pledge because of the impact resulting from their contribution to the success of a crowdfunding campaign. André et al. (2017) study reward crowdfunding success and posit that campaign success depends on the selfless support of backers. In contrast to this assumption, they find that most backer contributions follow a transactional logic, i.e., backers are pledging not for the benefit of the campaign creators.

\subsection{Self-determination theory and crowd funder motivation}

Self-determination theory is the dominant theoretical lens utilized to study backer motivation in crowdfunding (Allison et al. 2015; Cholakova and Clarysse 2015). SDT is considered a macro theory of human motivation and behavior (Ryan and Deci 2017). According to SDT, motivation is affected by three inherent psychological needs, the needs for competence, relatedness, and autonomy (Ryan and Deci 2000b; Vansteenkiste et al. 2010). The need for competence (White 1959) relates to the individuals' inherent urge to exert a meaningful effect on their surroundings, i.e., to investigate their environment and overcoming hurdles. The need for relatedness (Baumeister and Leary 1995) describes the experience of care and concern for others. The need for autonomy (De Charms 2013) relates to feelings of volition and psychological freedom. SDT posits that these needs motivate the self to manifest itself in behavior. In this regard, intrinsic motivation refers to behavior that is initiated for its own sake. Intrinsic motivation occurs when the inherent needs are satisfied, i.e., the behavior is interesting or joyful (autonomy); it is perceived as challenging (competence) or relevant to important others (relatedness). In contrast, extrinsic motivation refers to behavior that is initiated to obtain a separable external outcome and reflect tasks or activities that lack need satisfaction. SDT research found that people vary in terms of their type of motivation (intrinsic motivation or extrinsic motivation) and that offering rewards can either thwart or enhance the inherent psychological needs of individuals, thereby decreasing or increasing intrinsic and extrinsic motivation (Ryan and Deci 2000a).

The applicability of SDT to the crowdfunding context has been documented by two recent studies (Allison et al. 2015; Cholakova and Clarysse 2015). Allison et al. (2015) investigate linguistic cues in entrepreneurial narratives in microlending. The authors report that lending decisions are triggered by intrinsic cues as the microlenders are motivated by an inherent satisfaction or joy of giving. Cholakova and Clarysse (2015) use SDT to assess the extent to which financial and nonfinancial motivation affect crowd funders' decision to invest for equity or to pledge in a technology venture. They relate intrinsic and extrinsic motivation to the four previously identified backer motives in reward crowdfunding: collect rewards, help others, become part of a community, and support a cause (Gerber et al. 2012; Lin et al. 2014; Bretschneider and Leimeister 2017). Cholakova and Clarysse (2015) argue that backers' motivation to "collect rewards" is an extrinsic motive as backers receive an external financial return for their support. On the other hand, they consider the motives "to help others", "be part of a community", and "support a cause" as intrinsic backer motivation. However, the authors do not find that intrinsic motivation is of significant relevance to motivate backers to support crowdfunding projects, and they conclude that only extrinsic factors matter for the decision to pledge.

\subsection{Hypotheses development}

Central to SDT are different rewards, which thwart or enhance the inherent psychological needs (Ryan and Deci 2000a). However, most crowdfunding studies consider rewards only as acquiring "a new gadget or product" (Cholakova and Clarysse 2015, p. 154; Blaseg et al. 2020); although, entrepreneurs offer a portfolio of different rewards. Common reward types are pre-purchase rewards, i.e., product or service, symbolic rewards, i.e., thank-you note, or community rewards, i.e., involvement with project creators or other backers (Thürridl and Kamleitner 2016). Furthermore, entrepreneurs can also offer price-discounted rewards, make rewards exclusive by limiting the availability of a reward, or combine different rewards into reward bundles (Ibid.). The preference for one particular reward over another reveals a lot about a supporter's motivation, and in the 
following, we propose our hypotheses on how different rewards associate with backer motivation.

\subsubsection{Backer motivation in reward crowdfunding}

Before we delve into community differences, we propose that backers will be triggered primarily by pecuniary rewards. The central promise of reward crowdfunding is the offer of rewards as compensation for backers' financial support. Accordingly, in contrast to prosocial financing contexts such as micro-lending (Galak et al. 2011), backers should not be drawn to reward crowdfunding platforms out of altruism but to receive some form of return for their contribution (Cholakova and Clarysse 2015). In this regard, a popular assumption is that reward crowdfunding platforms resemble marketplaces such as Amazon, where consumers look for products but not more (Chan and Parhankangas 2017). As theories of consumer behavior suggest, there are different values why consumers buy products (Sheth et al. 1991; Sweeney and Soutar 2001). The primary driver of consumer choice is a product's functional value; the perceived utility derived from a product's functionality. An essential component of the functional value is the price (Sheth et al. 1991) and the perceived value for price (Sweeney and Soutar 2001). Accordingly, backers will likely look for rewards that offer salient pecuniary benefits such as price discounts. The theoretical model by Belleflamme et al. (2014) supports this view: The authors theorize that crowd funders are price-sensitive early consumers who want to pre-purchase a product. Also, Blaseg et al. (2020) argue that backers visit reward crowdfunding websites instead of other marketplaces because they are looking for better prices and early-bird deals. Thus, backers might look for rewards that offer the product for a reasonable price, such as discounted rewards. Besides, backers are often drawn to reward crowdfunding by the innovativeness of products and services on offer (Chan and Parhankangas 2017). In this respect, backers resemble early adopters who are attracted by the curiosity aroused through and the novelty provided by the reward offer, i.e., the epistemic value (Sheth et al. 1991). In this sense, pecuniary rewards fulfill an additional function: They compensate backers for the risk of buying an innovative, not fully developed product, which potentially never reaches the market or is delivered late (Mollick 2014).
Taken together, we expect backers to evaluate the reward by following market pricing logic (Allison et al. 2015). Consequently, neglecting any community differences, we expect that intrinsic motivation will be crowded out, and the extrinsic motivation of backers will be stimulated by the pecuniary benefits offered to backers from purchasing a given reward (Cholakova and Clarysse 2015).

Hypothesis 1: A pecuniary reward is positively associated with backers' motivation to pledge in a crowdfunding project.

\subsubsection{Motivation in distinct backer communities: cultural versus commercial backers}

Recent evidence by Josefy et al. (2017) suggests that sets of similar crowdfunding proposals draw on unique audiences or communities, in which individuals share a common interest. In reward crowdfunding, there are commercial campaigns but also campaigns initiated by entrepreneurs from the creative and cultural sectors. Cultural entrepreneurs exhibit a unique entrepreneurial profile as they do not only pursue an economic purpose but primarily want to create something of cultural value for the public (Throsby 2008; Dacin et al. 2010). Accordingly, cultural entrepreneurs likely appeal to a particular audience of cultural backers in crowdfunding. Such cultural backers might represent various culturally oriented groups, such as art connoisseurs or collectors, enthusiasts, or patrons who are consumers of arts, share a collective identity and appreciation for cultural products and understand the needs of cultural entrepreneurs. On the other hand, commercial backers might represent another community, i.e., an audience that highly values novel and functional products, and that matches the profile of commercial entrepreneurs, whose main goal is the creation of economic value (Parhankangas and Renko 2017). It is conceivable that these distinct backer audiences exhibit a fundamentally different motivation to support projects.

Pecuniary and symbolic rewards We propose that compared to cultural backers, commercial backers are more likely to be attracted by pecuniary rewards. Backers of commercial projects provide financial capital to entrepreneurs who seek to establish new products or services for consumer markets (Parhankangas and Renko 2017). 
Accordingly, backers of commercial projects should behave similarly to regular consumers and be driven by the prospects of receiving novel products at a reasonable price (Sweeney and Soutar 2001). Empirical evidence by Chan and Parhankangas (2017) supports this assumption: They study commercial technology projects and show that backers look for innovative but easy to use products on reward crowdfunding platforms. Also, Lin et al. (2014) consider commercial projects and find that backers mainly want to purchase the product in reward crowdfunding. Therefore, we expect backers of commercial projects to form a community of extrinsically motivated early-customers who wish to derive pecuniary benefits. An interview partner whom we asked about her or his motive to back commercial projects supported the relevance of pecuniary rewards in the community of commercial backers: "As a supporter of technology projects, new products are often available at lower prices." 2

Further, backer communities may also take into account the needs of the entrepreneurs they support. An entrepreneur who seeks capital for a profit-oriented cause follows an opportunistic goal, such as increasing her or his wealth (Cassar 2007). Therefore, it is unlikely that a profit-oriented entrepreneur arouses the need in others to provide capital selflessly. On the other hand, cultural entrepreneurs are likely to be perceived as in need of financial capital to create something of value not only for themselves but also for others (Baumol and Bowen 1993; Throsby 1994). In particular, the community of cultural backers might be aware of the cultural entrepreneurs' financing constraints (Konrad 2018) and might, therefore, provide capital selflessly. This is also highlighted by an interview partner: "I am an artist myself and know from my own experience how difficult it is to realize cultural projects without adequate financial support from third parties. Public funding sources are usually very difficult to reach. Yet culture is of upmost importance for a diverse, open-minded and considerate society". The quote demonstrates that cultural backers are willing to support cultural entrepreneurs in response to entrepreneurs' neediness and the perceived high relevance of cultural goods for the public. Kuppuswamy and Bayus (2017) find that

\footnotetext{
${ }^{2}$ We conducted five explorative interviews with three cultural backers and two commercial backers and asked about the motivation to support a particular campaign (cultural or commercial) and about the relevance of different rewards for their backing decision.
}

backers want to contribute to projects when they believe that their contribution makes an impact. In this regard, backers will likely perceive their support to a cultural entrepreneur in need and a project with a cultural purpose as particularly impactful.

Accordingly, we expect that cultural backers will respond more positively to rewards that indicate an intrinsic motive to help others and less to pecuniary rewards. Symbolic rewards correspond with salient altruistic motives. These rewards do not include a financial compensation, but only a purely symbolic gesture. Most importantly, symbolic rewards are of relatively low cost to the entrepreneur. Therefore, symbolic rewards are likely to be selected by backers out of a desire to help others. SDT suggests that offering a reward that is contingent on backers' decision to pledge can be perceived as controlling (Allison et al. 2015; Cholakova and Clarysse 2015). Purely offering something symbolic is likely to be perceived as noncontrolling and meets the need to feel autonomous (Ryan and Deci 2000b; De Charms 2013). Thus, offering a symbolic reward results in the crowding in of intrinsic motivation, which is important for backers who want to have an impact. We believe this is particularly applicable to backers who support cultural entrepreneurs. In summary, we anticipate that compared to commercial backers, cultural backers are less likely to pledge for pecuniary rewards but more likely to pledge for symbolic rewards, and vice versa.

Hypothesis 2a: A pecuniary reward is less positively associated with backers' motivation to pledge in a cultural crowdfunding project than in a commercial crowdfunding project.

Hypothesis 2b: A symbolic reward is more positively associated with backers' motivation to pledge in a cultural crowdfunding project than in a commercial crowdfunding project.

Community rewards Community rewards are nonfinancial rewards that typically involve social interactions with the campaign creators and other community members. Such rewards enhance backers' need for relatedness, which in turn, crowds in intrinsic motivation (Baumeister and Leary 1995). Community rewards allow backers to become an active part of their 
community. For several reasons, we believe that community rewards appeal in particular to the motivation of cultural backers. First, relatedness - concern and care for others (Ryan and Deci 2017) — is a vital need in communities from the cultural and creative sectors because of the high dependency on individual community members. For instance, empirical evidence of Woronkowicz and Noonan (2019) shows that artist worker concentration in a geographic location is an important determinant of cultural entrepreneurship. They explain this finding by the importance of networks and synergies among community members. In contrast to cultural projects, commercial ventures tend to have an easier path to becoming self-sufficient based on their revenues (Baumol and Bowen 1993; Throsby 1994). Second, consumers of the arts and other stakeholders enjoy becoming involved in cultural projects that offer the perception of a shared identity. This is empirically shown by Josefy et al. (2017) who demonstrate that a distinct community of backers supports their local theater because of common interests and values. Community rewards allow cultural backers to feel meaningfully connected and valued by others with similar interests or ideals. Consequently, cultural backers might pledge for community rewards to be liked by others and, notably, by individuals whom the backers deem important or prominent. As confirmed by interview partners, cultural backers might be artists or cultural entrepreneurs themselves who feel a sense of belonging and desire to interact with other creatives. In this regard, the group of cultural backers might appreciate the high social value of community rewards, which provide value in terms of group membership (Sheth et al. 1991). The relevance of social values might be less pronounced in communities of commercial backers who are mainly interested in the functionality of new technological products (Chan and Parhankangas 2017). Third, community rewards often have the purpose of involving backers in the value creation process. This is echoed in an interview with a backer of cultural projects: "For me personally this kind of offer (i.e., community reward) is the most interesting because you can be part of a creative process and at the same time get a personal insight, which you cannot get through a merchandising product." While there are undoubtedly commercial backers who are also interested in interacting with the founders, this might overall be less relevant for a backer community who is primarily looking for new products. In particular, commercial projects often launch the products rapidly after the crowdfunding campaign on other marketplaces (Blaseg et al. 2020), indicating that most decisions on product development have been made. Therefore, the active involvement of backers in the value creation process also becomes less attractive for commercial backers. We anticipate that community rewards will trigger a more positive backing response from cultural backers compared to commercial backers.

Hypothesis 3: A community reward is more positively associated with backers' motivation to pledge in a cultural crowdfunding project than in a commercial crowdfunding project.

\section{Method}

\subsection{Data}

To test our hypotheses, we draw on data from Startnext, the largest reward crowdfunding platform in the German-speaking region. This platform has around 1.6 million registered users and generated approximately $€ 100$ million of funding for entrepreneurs since it was established in 2010. Startnext operates similar to other reward crowdfunding platforms such as Kickstarter or Indiegogo and connects project creators with backers. It facilitates the financing of a variety of entrepreneurial venture- or project-based initiatives in different fields and industries. Most project categories on Startnext are from the arts and the creative and cultural sectors, but the platform also features entrepreneurs with for-profit oriented technology campaigns. The funding is based on an all-or-nothing principle: If entrepreneurs do not reach their funding goal, backers will receive a refund.

We base our categorization of cultural and commercial projects on qualitative insights gained through interviewing staff from Startnext before our data collection. Startnext allows entrepreneurs to indicate a primary and optional secondary campaign category to reflect the entrepreneurs' industry affiliations. Following prior categorizations (Throsby 2008) and the interview insights, we decided to use projects from the primary categories of theater and art projects to represent cultural projects. Our sample comprises the full breadths of possible industries in both sectors (i.e., fine art, concept art, music art, visual art, performing art, theater 
ensembles). For commercial projects, we used projects from the primary categories of technology and invention, in line with Parhankangas and Renko (2017). These categories usually include projects initiated by entrepreneurs that aim at creating new knowledge- or technology-intensive products or services for consumer markets (e.g., consumer technology, information technology, health care). ${ }^{3}$

The goal was to create a generalizable dataset, and therefore, we considered all 1700 projects in the indicated categories published between 2015 and 2020the complete set of projects in this time frame. To align with our study purpose on entrepreneurial projects and in line with Mollick (2014), we consider only projects with funding requests above $€ 5000$, excluding the smaller, non-entrepreneurial projects. From a total of 454 commercial projects, 117 satisfied our campaign size inclusion criterion, and from a total of 1246 cultural projects, 341 met our inclusion criterion. To have comparable group sizes, we randomly selected 150 cultural projects. Individual projects can offer multiple rewards; therefore, we disaggregated our sample in a multi-level dataset consisting of projects and respective reward levels. After excluding projects with no variation in the demand for rewards, i.e., where no pledges had been made for any of the rewards offered, our final sample consisted of 91 commercial and 134 cultural projects, of which $47.5 \%$ were successful in generating the funds desired. Around $50 \%$ of the campaigns were initiated after 2017, and the average funding goals were 19,000€, with the largest goal being $300,000 €$. The average number of backers for a project is 76, with 1938 being the highest number of backers for a campaign.

\subsection{Variables}

\subsubsection{Dependent variables}

We use two dependent variables to measure backer motivation. The measures are based on backers' financing decisions on reward level and in accordance with dependent variables used in previous crowdfunding studies (e.g., Ahlers et al. 2015; Allison et al. 2015; Cholakova and Clarysse 2015). Firstly, we defined the

\footnotetext{
${ }^{3}$ To exclude potential cases of hybrid ventures (Moss et al. 2018), we also considered the secondary category and tested whether there is an overlap of different types of commercial, cultural, and social entrepreneurship (Parhankangas and Renko 2017). However, the results remain consistent if we drop hybrid projects from our analysis.
}

Number of Backers as the number of backers who pledged for reward $z$ in project $i$. Secondly, we employed the dependent variable Amount Pledged ( $€$ ) as the level of funding raised by reward $\mathrm{z}$ in a project $\mathrm{i}$.

\subsubsection{Explanatory variables}

The variable Culture takes the value 1 if a project's main category is theater and arts while commercial projects serve as the reference group. The Pecuniary Reward variable indicates whether reward $z$ involves a discount on the price offered during the crowdfunding campaign compared to the price after the campaign, e.g., a theater project offers discounted entrance tickets for a performance during the crowdfunding campaign compared to the price at the box office. Price discounts are typically promoted as an "early-bird" offer (Blaseg et al. 2020). As the level of the discount is not specified in all rewards, the variable Pecuniary Reward is a dummy $(1 / 0)$. An example of a pecuniary reward is as follows: "1x heat_it_Android - Startnext special deal. One heat it for your Android Smartphone for a Startnext special deal. Save $20 \%$ compared to the planned sales price."

We also created the dummy variable Symbolic Reward, which refers to rewards without any tangible compensation. Symbolic rewards may include affirmative gestures such as thank-you notes (Thürridl and Kamleitner 2016). Importantly, symbolic rewards never include a product or usable item as a form of compensation. An example of a symbolic reward is the following: "Virtual hug. A big hug for your solidarity and for saving our cultural scene".

We denoted the variable Community Reward, with the value 1 , for rewards facilitating a social bond between the supporter and the founders and/or other backers. These rewards are designed to encourage backers to get involved in the community and to be part of the project, for example, by actively discussing the mission, project idea, or product. Concretely, community rewards are often joint social activities with the founders and other backers. Importantly, these rewards do not include business-related activities (e.g., a theater play's rehearsal). The following example indicates a community reward: "Meet the founders in the beautiful city of Freiburg and exchange ideas with the founders during a leisurely afternoon with a city tour and dinner." 


\subsubsection{Control variables}

We created additional variables to control for other possible influences on the demand for individual rewards. Competing Rewards is the number of rewards offered by entrepreneurs in their campaign. A higher number of rewards offered could potentially reduce the demand for a single reward. Gimmick is a dummy variable, indicating whether reward $z$ includes a material value that is not the product. Gimmick rewards often include t-shirts, bags, or tangible items not related to the entrepreneurs' regular product or service offering. Purchase is a dummy variable that indicates whether the main product of an entrepreneurial project is offered. For example, cultural projects might offer a canvas for sale, and theater projects might offer entrance tickets for a performance. Commercial projects might offer a new technological product, for example, an innovative magnetic smartphone adapter. Bundle refers to the number of different rewards that are offered together in reward $z$. Some rewards include the main product along with a gimmick and occasionally even more rewards. Price is the amount of money in Euros that the backers must pay to receive a certain reward. Due to the high standard deviations of this variable, we use the natural logarithm (Ln.Price) in our regression analysis. We created a variable Delivery for the promised delivery time, calculated as the difference between the start of the funding campaign and the indicated delivery date in months. It is conceivable that a reward promised far in the future may indicate that a product is less developed and more uncertain, potentially causing delays in the delivery (Mollick 2014). We also denoted a variable Scarce $(1 / 0)$, which shows whether a reward is of limited supply, i.e., availability is smaller than 50 . Backers potentially appreciate such an exclusivity of rewards. In addition to the control variables reported, we employed random effects to control for differences in the general project quality (described in the next section).

\subsection{Econometric analysis}

Both dependent variables are non-normal, but Poisson distributed. Many rewards have little or no demand-resulting in low values for both the dependent variables. Also, our dependent variables cannot take negative values. Therefore, Poisson regression models are a suitable estimation model for our data (Cameron and Trivedi 2013). Furthermore, our multi- level data allows us to incorporate random or fixed effects (cf. Kuppuwamy and Bayus 2017). Hausman tests led us to dismiss fixed effects and apply random effects as a more consistent estimator for our data (Cameron and Trivedi 2013). Employing random project effects allowed us to control for all rewardindependent heterogeneity, e.g., criteria that relate to backers' perception of a project's quality in general such as video quality, patents, endorsement for the project, and team experience (e.g., Courtney et al. 2017). This is crucial as rewards are nested within a specific project; if the project is not attractive, the individual rewards are unlikely to be in high demand. A similar concern pertains to the standard errors; we used clustered robust standard errors at the project level in all our estimations. ${ }^{4}$

\section{Analysis}

\subsection{Descriptive statistics}

Our sample consists of 2334 rewards from 225 projects. Table 1 outlines the descriptive statistics for cultural and commercial projects and the full sample. A project offers, on average, 13.4 rewards. Rewards in cultural projects compete on average with more other rewards (14.91) than rewards in commercial projects (10.27). A reward is backed, on average, 6.45 times with a minimum of 0 and a maximum of 786 backers. Rewards generate an average revenue of $€ 536.40$ for entrepreneurs; however, this amount has a substantial standard deviation potentially due to outliers attracting large funding amounts. The amount pledged also differs for cultural and commercial projects: Commercial projects generate, on average, more than twice as much revenue in return for a single reward (845.91€ vs. 386.67€). Another significant difference is the average reward price: The price is on average $€ 557.19$ in commercial projects compared to $€ 391.46$ in cultural projects. Overall, $19 \%$ of commercial rewards offer a price discount, compared to only $6 \%$ of cultural rewards. Symbolic rewards and community rewards are more common in cultural projects, accounting for $0.15 \%$ and $0.18 \%$,

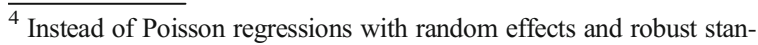
dard errors clustered at the project level, we employ robustness tests with Poisson regressions with fixed effects and bootstrapped clustered standard errors. Our results remain consistent.
} 
Table 1 Descriptive statistics

\begin{tabular}{|c|c|c|c|c|c|c|}
\hline & \multirow{2}{*}{$\begin{array}{l}\text { Culture = } 1 \\
\text { Mean }\end{array}$} & \multirow{2}{*}{$\begin{array}{l}\text { Culture }=0 \\
\text { Mean }\end{array}$} & \multicolumn{4}{|l|}{ Overall } \\
\hline & & & Mean & SD. & Min & Max \\
\hline Number of backers & 5.60 & 8.19 & 6.45 & 26.59 & 0 & 786 \\
\hline Amount pledged $(€)$ & 386.67 & 845.91 & 536.40 & 2711.35 & 0 & 77,256 \\
\hline Competing rewards & 14.91 & 10.27 & 13.40 & 7.01 & 2 & 37 \\
\hline Gimmick & 0.23 & 0.20 & 0.22 & 0.41 & 0 & 1 \\
\hline Purchase & 0.60 & 0.62 & 0.61 & 0.49 & 0 & 1 \\
\hline Bundle & 0.08 & 0.10 & 0.09 & 0.45 & 0 & 7 \\
\hline Price & 391.46 & 557.19 & 445.50 & 1990.96 & 5 & 54,537 \\
\hline Delivery & 4.70 & 4.71 & 4.71 & 4.07 & 0 & 39 \\
\hline Scarce & 0.48 & 0.29 & 0.42 & 0.49 & 0 & 1 \\
\hline Pecuniary reward & 0.06 & 0.19 & 0.11 & 0.31 & 0 & 1 \\
\hline Symbolic reward & 0.15 & 0.11 & 0.13 & 0.34 & 0 & 1 \\
\hline Community reward & 0.18 & 0.09 & 0.15 & 0.36 & 0 & 1 \\
\hline Culture & 1 & 0 & 0.67 & 0.47 & 0 & 1 \\
\hline Observations & 1573 & 761 & 2334 & & & \\
\hline
\end{tabular}

respectively; in commercial projects, the comparable figures are $0.11 \%$ and $0.09 \%$. Table A1 in appendix 1 in the Electronic Supplementary Material (ESM) shows the correlations among the variables. Correlations are low, and multicollinearity is not of concern for our regression analyses.

\subsection{Regression results}

Tables 2 and 3 show the regression results for the Number of Backers and the Amount Pledged $(€)$, respectively. Before we turn to our hypotheses, we interpret significant control variables from model 1 and model 6 .

Table 2 Poisson regression for the dependent variable number of backers

\begin{tabular}{|c|c|c|c|c|c|}
\hline Model & 1 & 2 & 3 & 4 & 5 \\
\hline Competing rewards & $-0.01(0.03)$ & $0(0.03)$ & $-0.01(0.03)$ & $0(0.03)$ & $0(0.03)$ \\
\hline Gimmick & $0.02(0.14)$ & $0.04(0.14)$ & $0.01(0.14)$ & $0.04(0.13)$ & $0.05(0.13)$ \\
\hline Purchase & $1.05(0.16)^{* * *}$ & $1.06(0.15)^{* * *}$ & $1.04(0.16)^{* * *}$ & $1.03(0.15)^{* * *}$ & $1.03(0.14)^{* * *}$ \\
\hline Bundle & $-0.26(0.1)^{* * *}$ & $-0.26(0.08)^{* * *}$ & $-0.26(0.1)^{* * *}$ & $-0.29(0.09)^{* * *}$ & $-0.3(0.08)^{* * *}$ \\
\hline Ln.Price & $-0.49(0.05) * * *$ & $-0.49(0.05)^{* * *}$ & $-0.49(0.05) * * *$ & $-0.47(0.05)^{* * *}$ & $-0.48(0.05)^{* * *}$ \\
\hline Delivery & $-0.05(0.02)^{* *}$ & $-0.05(0.02)^{* *}$ & $-0.05(0.02)^{* *}$ & $-0.05(0.02)^{* *}$ & $-0.05(0.02)^{* *}$ \\
\hline Scarce & $-0.65(0.12)^{* * *}$ & $-0.65(0.12)^{* * *}$ & $-0.64(0.12)^{* * *}$ & $-0.66(0.13)^{* * *}$ & $-0.66(0.13)^{* * *}$ \\
\hline Pecuniary reward & $0.77(0.13)^{* * *}$ & $1.03(0.17)^{* * *}$ & $0.75(0.14)^{* * *}$ & $0.76(0.13)^{* * *}$ & $0.97(0.21)^{* * *}$ \\
\hline Symbolic reward & $-0.23(0.16)$ & $-0.21(0.15)$ & $-0.38(0.31)$ & $-0.18(0.15)$ & $-0.22(0.3)$ \\
\hline Community reward & $-0.45(0.28)$ & $-0.47(0.28)^{*}$ & $-0.44(0.27)$ & $-1.37(0.55)^{* *}$ & $-1.3(0.56)^{* *}$ \\
\hline Culture & $0.09(0.26)$ & $0.2(0.27)$ & $0.04(0.29)$ & $0.04(0.28)$ & $0.13(0.33)$ \\
\hline Culture*pecuniary reward & & $-0.81(0.27)^{* * *}$ & & & $-0.7(0.29)^{* *}$ \\
\hline Culture*symbolic reward & & & $0.22(0.36)$ & & $0.08(0.37)$ \\
\hline Culture*community reward & & & & $1.17 * *(0.56)$ & $1.06^{*}(0.59)^{*}$ \\
\hline Project effects & Yes & Yes & Yes & Yes & Yes \\
\hline Wald chi ${ }^{2}$ & $642.6^{* * *}$ & $758.79 * * *$ & $648.13^{* * *}$ & $698.64 * * *$ & $815.94 * * *$ \\
\hline
\end{tabular}

*** $p<0.01, * * p<0.05, * p<0.1$. Dependent variable is number of backers. Robust standard errors clustered at project level in parentheses 
Table 3 Poisson regression for the dependent variable amount pledged $(€)$

\begin{tabular}{|c|c|c|c|c|c|}
\hline Model & 6 & 7 & 8 & 9 & 10 \\
\hline Competing rewards & $-0.02(0.02)$ & $-0.01(0.02)$ & $-0.02(0.02)$ & $-0.02(0.03)$ & $-0.01(0.02)$ \\
\hline Gimmick & $-0.37(0.15)^{* *}$ & $-0.34(0.14)^{* *}$ & $-0.38(0.15)^{* *}$ & $-0.34(0.15)^{* *}$ & $-0.31(0.14)^{* *}$ \\
\hline Purchase & $0.46(0.18)^{* * *}$ & $0.48(0.17)^{* * *}$ & $0.46(0.18)^{* *}$ & $0.44(0.17)^{* *}$ & $0.47(0.17)^{* * *}$ \\
\hline Bundle & $-0.07(0.1)$ & $-0.09(0.1)$ & $-0.07(0.1)$ & $-0.09(0.1)$ & $-0.11(0.1)$ \\
\hline Ln.Price & $0.31(0.05)^{* * *}$ & $0.31(0.05)^{* * *}$ & $0.31(0.05)^{* * *}$ & $0.31(0.04)^{* * *}$ & $0.31(0.04)^{* * *}$ \\
\hline Delivery & $-0.03(0.03)$ & $-0.03(0.03)$ & $-0.03(0.03)$ & $-0.03(0.03)$ & $-0.03(0.03)$ \\
\hline Scarce & $-0.53(0.17)^{* * *}$ & $-0.54(0.17)^{* * *}$ & $-0.53(0.17)^{* * *}$ & $-0.52(0.18)^{* * *}$ & $-0.53(0.18)^{* * *}$ \\
\hline Pecuniary reward & $0.8(0.25)^{* * *}$ & $1.03(0.28)^{* * *}$ & $0.79(0.26)^{* * *}$ & $0.79(0.25)^{* * *}$ & $1(0.3)^{* * *}$ \\
\hline Symbolic reward & $-0.54(0.21)^{* *}$ & $-0.52(0.21)^{* *}$ & $-0.68(0.38)^{*}$ & $-0.51(0.2)^{* *}$ & $-0.57(0.35)$ \\
\hline Community reward & $-0.49(0.26)^{*}$ & $-0.5(0.26)^{*}$ & $-0.48(0.26)^{*}$ & $-0.9(0.59)$ & $-0.84(0.58)$ \\
\hline Culture & $-0.28(0.25)$ & $-0.17(0.27)$ & $-0.32(0.26)$ & $-0.35(0.29)$ & $-0.26(0.33)$ \\
\hline Culture*pecuniary reward & & $-0.83(0.28) * * *$ & & & $-0.77(0.3)^{* *}$ \\
\hline Culture*symbolic reward & & & $0.23(0.41)$ & & $0.11(0.4)$ \\
\hline Culture*community reward & & & & $0.53(0.63)$ & $0.44(0.64)$ \\
\hline Project effects & Yes & Yes & Yes & Yes & Yes \\
\hline Wald chi $^{2}$ & $4575.07 * * *$ & $4468.04 * * *$ & $4760.92 * * *$ & $4610.3 * * *$ & $4858.65 * * *$ \\
\hline
\end{tabular}

*** $p<0.01, * * p<0.05, * p<0.1$. Dependent variable is amount pledged $(€)$. Robust standard errors clustered at project level in parentheses

For ease of interpretation, it is useful to calculate the incidence rate ratios (IRR) of the coefficients in Poisson regression models, i.e., the exponentiated coefficients which are interpretable as the ratio of two incidence rates (Cameron and Trivedi 2013). Rewards involving a product are associated with more backers $(\exp (1.05)=$ $2.86)$ and higher funding amounts $(\exp (0.46)=1.58)$. On the other hand, scarce rewards are associated with fewer backers $(\exp (-0.65)=0.52)$ and lower funding amounts $(\exp (-0.53)=0.59)$, compared to rewards that are not exclusive. Interestingly, a higher reward price reduces the number of backers $(\exp (-0.49)=0.61)$ but increases the level of funding pledged $(\exp (0.31)=$ 1.36). Accordingly, expensive rewards generate higher revenues but are subject to lower demand. Offering bundles in a reward $(\exp (-0.26)=0,77)$ and longer delivery times $(\exp (-0.05)=0.95)$ reduce the number of backers.

In the next step, we turn to our hypotheses. We find support for Hypothesis 1: Pecuniary rewards are highly attractive for backers, i.e., rewards involving a price discount increase the number of backers and the amount pledged significantly. The effect is of econometric magnitude. Compared to rewards without price discounts, rewards with price discounts have a rate of 2.16 times greater for Number of Backers $(\exp (0.77)=2.16)$ and a rate 2.23 times greater for Amount Pledged $(\epsilon)$ $(\exp (-0.26)=0.77)$. Hypotheses $2 \mathrm{a}, 2 \mathrm{~b}$, and 3 focus on the motivational differences between cultural and commercial projects. First, we find generally no significant difference in the demand for rewards in the distinct backer communities, i.e., the main effect of Culture is insignificant for both dependent variables. Hypothesis 2 a proposes that pecuniary rewards are less relevant for motivating cultural backers compared to commercial backers. We find strong empirical support for this hypothesis. For ease of interpretation, we use the average marginal effects to portray the interaction effects in the graphs in Fig. 1a, b. While pecuniary rewards increase the number of backers by $178.9 \%$ for commercial projects, they increase the number of backers by only $23.7 \%$ for cultural projects (Fig. 1a). We observe a similarly strong effect for the amount pledged, pecuniary rewards increase the amount pledged by $178.7 \%$ in a commercial project; however, pecuniary rewards increase the amount pledged in cultural projects by only $22.2 \%$ (Fig. 1b). Hypothesis $2 \mathrm{~b}$ predicts that symbolic rewards are more relevant for motivating cultural backers. We find that symbolic rewards have no significant influence on the number of backers and significantly reduces the amount pledged $(\exp (-0.54)=0.58)$. Surprisingly, symbolic rewards are not significantly more important for cultural projects, leading us to reject Hypothesis 2b. For Hypothesis 3, which posits that 
a) Culture*Pecuniary reward
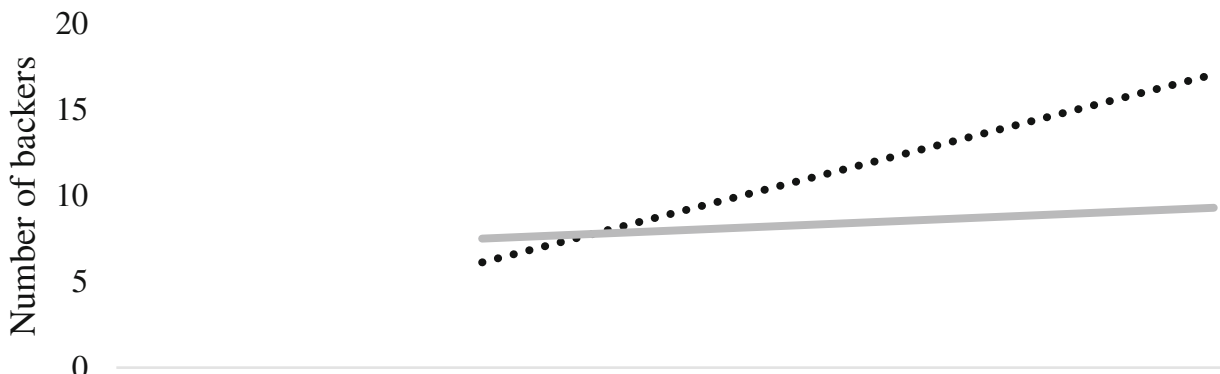

0

Pecuniary reward $=0 \quad$ Pecuniary reward $=1$

Culture $=0 \quad$ Culture $=1$

b) Culture*Pecuniary reward
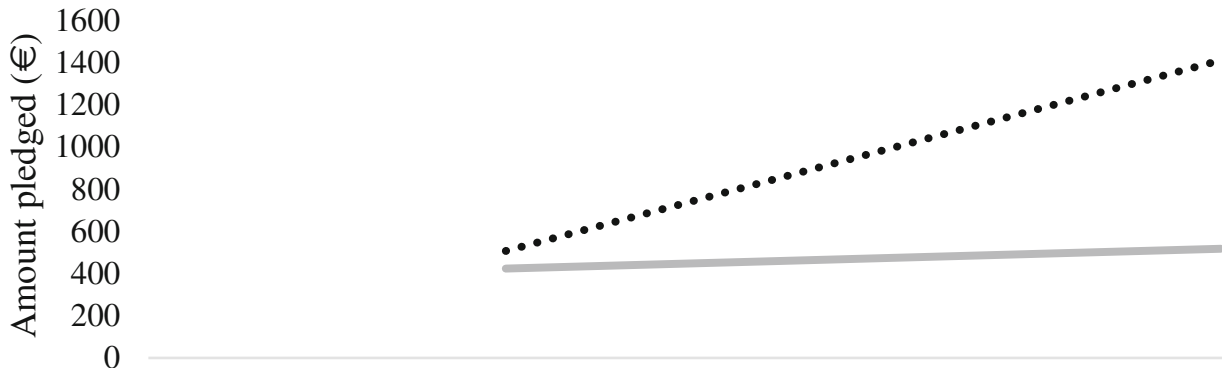

0

Pecuniary reward $=0$

Pecuniary reward $=1$

•.... Culture $=0 \quad$ Culture $=1$

c) Culture*Community reward
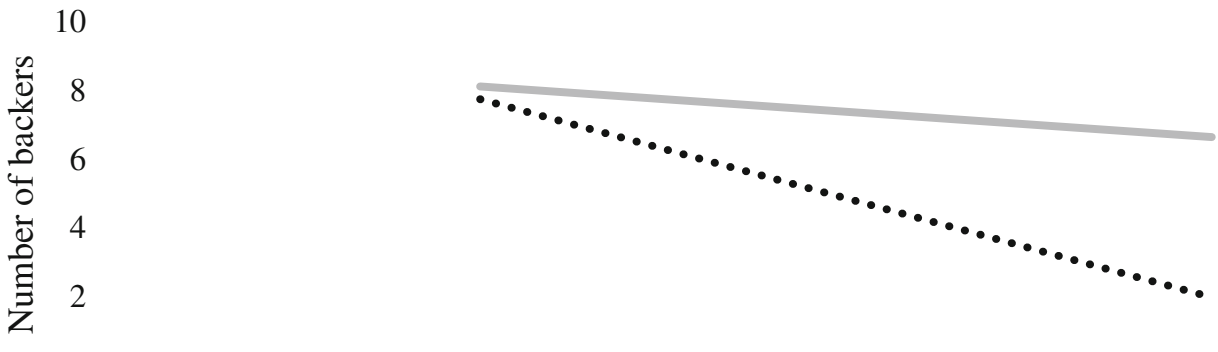

0

Community reward $=0$ Community reward $=1$

-... Culture $=0 \quad$ Culture $=1$

Fig. 1 Interaction graphs

community rewards are more relevant for motivating cultural backers than commercial backers, we find moderate support. As hypothesized, the moderation effect between Culture and Community Reward is significant and positive for the Number of Backers. This interaction is portrayed in the graph in Fig. 1c for ease of 
interpretation. The effect is of high econometric magnitude. Community rewards are $235.9 \%$ more effective in attracting backers for cultural than for commercial projects (Fig. 1c). The moderation effect is also positive for the amount pledged but insignificant.

We have executed several additional analyses to rule out alternative explanations for the tested relationships; these can be found in Appendix 2 in the ESM.

\section{Discussion}

In this study, we set out to examine the motivation of backers to pledge for rewards in the distinct communities of cultural and commercial backers. Leveraging SDT (Ryan and Deci 2017), our study points to fundamental motivational differences in both communities. Commercial backers appear as early-customers who search for good product deals. Cultural backers, on the other hand, are keen to become part of the cultural community and derive utility from rewards that allow engagement with the cultural community. Surprisingly, our results suggest that altruism and selfless support to help others is of low relevance in either community, in contrast to previous findings. The main differences in both communities relate to the importance of pecuniary and community rewards. The relative effect of price discounts is at least seven times higher for motivating commercial compared to cultural backers. However, this result must be put into context: It does not suggest that pecuniary rewards are irrelevant for cultural backers. Cultural backers also want to purchase the project's main offering such as a canvas or theater tickets, and they also appreciate price discounts, but much less than commercial backers. Unique in the cultural backer community is the backers' intrinsic need for relatedness. In contrast to commercial backers, cultural backers pledge more frequently for community rewards due to their desire to feel meaningfully connected with the entrepreneurs and become an active part of the cultural value creation process.

\subsection{Theoretical and practical contributions}

Our paper makes several contributions to the academic literature on crowdfunding and research on cultural entrepreneurship. First, our study adds to the growing literature on backer motivation in crowdfunding. While crowdfunding research has provided a clear picture for intrinsically motivated backers in the prosocial microlending context (Galak et al. 2011; Allison et al. 2015) and extrinsically motivated investors in equity crowdfunding (Ahlers et al. 2015; Kleinert et al. 2020), the picture is more blurred in reward crowdfunding. The evidence is inconclusive with several studies pointing to extrinsic financial motives of backers (Lin et al. 2014; Cholakova and Clarysse 2015), while other studies point to intrinsic motivations such as help others or become part of a community (Gerber et al. 2012; Kuppuswamy and Bayus 2017; Nielsen and Binder 2020). Our study introduces a new approach in that we study the central element of SDT and reward crowdfunding, that is, rewards that appeal to the intrinsic and extrinsic motivation of individuals (Deci et al. 1999). Our results contribute to the ongoing discussion by challenging the predominant notion of homogeneous backer motivation and the attendant relevance of extrinsic and intrinsic factors in reward crowdfunding.

Our results are pointing to a salient relevance of backers' extrinsic motive to pledge; the main product on offer motivates backers to pledge, and backers are particularly responsive to pecuniary benefits such as price discounts. Furthermore, symbolic rewards that correspond with altruistic intrinsic motivation to help others (Gerber et al. 2012) are not relevant for backers' decision to pledge. Nevertheless, our study makes a significant contribution to the scientific discourse in that we show that backers should not be considered as a homogenous group. Previous studies have often disregarded the industry heterogeneity in reward crowdfunding (Lin et al. 2014; Cholakova and Clarysse 2015). In this regard, Cholakova and Clarysse (2015, p. 160) have invited future research to investigate the backer motivation for "projects from different sectors, such as the social and the creative ones." Our study corresponds to this call and shows that distinguishing among different backer communities is crucial to understand their motivation. For example, our empirical results highlight that the need for relatedness (Ryan and Deci 2000b) is considerably more prevalent for the group of backers who support projects from the cultural compared to commercial sectors. Cultural backers want to engage in their community, whereas this motivation seems irrelevant for commercial backers. Furthermore, not all backers perceive extrinsic rewards as equally motivating; while they are essential to motivate commercial backers, they are significantly 
less relevant in motivating cultural backers. This finding is of interest for future research on the crowdfunding context and underlines the need to consider the heterogeneity of backers in cross-sectoral crowdfunding settings more carefully.

Second, our study adds to the recent conversation on crowdfunding communities. Some studies have emphasized that the community of backers has a central role in crowdfunding (Belleflamme et al. 2014; Josefy et al. 2017; Murray et al. 2020), yet the conversation of backer communities has only started. For instance, Belleflamme et al. (2014) suggest that communities differ from reward to equity crowdfunding. Josefy et al. (2017) show that within reward crowdfunding, similar campaigns are typically supported by specific communities. The authors stress that these communities consist of like-minded individuals with a common interest and shared values. In our study, we argue that communities will form around the different purposes of the entrepreneur, that is, entrepreneurs who seek to establish a profitable business (Parhankangas and Renko 2017) or entrepreneurs who are less devoted to establishing a profit-oriented venture but instead seek the creation of cultural values (Dacin et al. 2010). We introduce and compare two distinct communities: cultural and commercial backers. These two distinct backer communities derive fundamentally different utilities from backing projects and appreciate different consumption values (Sheth et al. 1991; Sweeney and Soutar 2001). Commercial backers behave similarly to early-customers and share an interest in new and functional products: They require a financial incentive to support a project. Interestingly, the classical consumption values such as functionality and price are less relevant for cultural backers. They are less responsive to pecuniary benefits and appreciate becoming an active part of their community and contributing to the process of cultural value creation. Thereby, our study conforms with the call for research by Josefy et al. (2017, p. 177), who invoke scholars to investigate "additional attributes of crowd communities that impact the success in this new and exciting form of venture funding." Our study corresponds to this call by showing that an important attribute in crowdfunding communities is the utility backers derive from pledging. Accordingly, different backer communities vary in their motivation and, therefore, respond differently to pecuniary and community rewards.

Third, entrepreneurs from the arts, the creative and cultural sectors - so-called cultural entrepreneurs, are a distinct type in the entrepreneurship landscape whose principal motive is to establish something of cultural value (see Dacin et al. 2010 for a discussion). Previous research has focused primarily on commercial entrepreneurs and more recently on social entrepreneurs and how both types of entrepreneurs mobilize resources (Parhankangas and Renko 2017). Cultural entrepreneurship, however, has received little scholarly attention in the mainstream entrepreneurship literature, despite their relevance for regional development, urban renewal, and revitalization (Bürger and Volkmann 2020). In particular, how cultural entrepreneurs can access early-stage financing is an important question (Konrad 2018) with practical relevance, given that in contrast to commercial entrepreneurs, funding options for entrepreneurs operating in the arts, creative, and cultural spheres are scarce (Baumol and Bowen 1993; Throsby 1994; Stevenson et al. 2019). Our study demonstrates that reward crowdfunding can be a promising way to finance new cultural ventures. Concretely, we advance the understanding of the role of community for cultural entrepreneurs. While we know that cultural communities are central for individuals to become self-employed in the cultural sectors (Woronkowicz and Noonan 2019), we show that community involvement is an essential asset for cultural crowdfunding campaigns.

Finally, our study provides actionable implications, especially for practicing entrepreneurs. Knowing which reward characteristics trigger pledges is crucial for entrepreneurs when designing the reward portfolio for their crowdfunding campaign. By providing discounts as rewards, both commercial and cultural entrepreneurs increase the likelihood of attracting backers. Every project in our sample offers at least one symbolic reward in their portfolio; however, these rewards play a minor role in all funding campaigns. Overall, our study shows that backers of both project types do not support projects without return expectations. However, commercial backers are much more similar to regular consumers and care about price and functionality. In contrast, cultural backers also seek additional satisfaction through participation and involvement with entrepreneurs and other backers.

\subsection{Limitations and avenues for future research}

This paper is not without limitations, which, together with our findings provide fruitful avenues for future research. Our study is limited to the Startnext categories arts, theater, technology, and invention. Although this 
categorization is established (Throsby 2008), the results might not be representative for all cultural and commercial projects. In particular, we believe it is fruitful to more closely study differences between backing communities for campaigns from more commercially oriented cultural industries, such as in film, music, design or gaming, where entrepreneurs have the potential to offer scalable products and which resemble more conventional forms of entrepreneurship (Dacin et al. 2010).

Relatedly, recent crowdfunding literature has considered hybrid ventures, i.e., entrepreneurs pursuing multiple causes simultaneously (Moss et al. 2018). We accounted for hybrid ventures by considering whether crowdfunding campaigns in our sample were assigned to more than one category. On Startnext, entrepreneurs who are pursuing social motives typically indicate "Social Business" as a primary or secondary category; however, this was only the case for a minor number of projects and did not affect our results. We believe that future research can use our findings as a starting point to investigate the backer motivation for other purposedriven campaigns, such as sustainable, social, or hybrid projects. Our results show that commercial backers constitute a community motivated by extrinsic pecuniary rewards, in contrast to cultural backers who form a community motivated by community rewards. It is conceivable that "social backers" or "sustainability backers" form distinct communities too. For instance, altruism and symbolic rewards may be more central for backers of social or sustainable projects.

An additional limitation might relate to our dataset. Reward crowdfunding studies predominantly rely on Kickstarter data (Courtney et al. 2017; Josefy et al. 2017; Parhankangas and Renko 2017); we use data from the largest German crowdfunding platform Startnext as a promising alternative. However, this platform does not allow us to observe social relationships among individual backers and project creators. For example, backers might have been project creators themselves and repay the support they received for their campaign and, thus, pledge for a project out of reciprocity (André et al. 2017). It remains an avenue for future research whether this type of reciprocal giving accounts for a significant fraction of backing decisions.

Acknowledgments The paper benefited from feedback received from the participants of the 'Leveraging Creativity' research workshop and symposium organized by the Center for Cultural Affairs at the O'Neill School of Public and Environmental Affairs at Indiana University and Purdue University, USA. Also, the authors thank Christine Volkmann and Doug Noonan for insightful comments. Moreover, we want to thank the reviewers who offered constructive feedback and helpful suggestions to improve this paper.

Funding Open Access funding enabled and organized by Projekt DEAL.

Conflict of interest The authors declare that they have no conflicts of interest.

All authors certify that they have no affiliations with or involvement in any organization or entity with any financial interest or non-financial interest in the subject matter or materials discussed in this manuscript.

Open Access This article is licensed under a Creative Commons Attribution 4.0 International License, which permits use, sharing, adaptation, distribution and reproduction in any medium or format, as long as you give appropriate credit to the original author(s) and the source, provide a link to the Creative Commons licence, and indicate if changes were made. The images or other third party material in this article are included in the article's Creative Commons licence, unless indicated otherwise in a credit line to the material. If material is not included in the article's Creative Commons licence and your intended use is not permitted by statutory regulation or exceeds the permitted use, you will need to obtain permission directly from the copyright holder. To view a copy of this licence, visit http://creativecommons.org/licenses/by/4.0/.

\section{References}

Ahlers, G. K., Cumming, D., Günther, C., \& Schweizer, D. (2015). Signaling in equity crowdfunding. Entrepreneurship Theory and Practice. https://doi. org/10.1111/etap.12157.

Allison, T. H., Davis, B. C., Short, J. C., \& Webb, J. W. (2015). Crowdfunding in a prosocial microlending environment: examining the role of intrinsic versus extrinsic cues. Entrepreneurship Theory and Practice. https://doi. org/10.1111/etap.12108.

André, K., Bureau, S., Gautier, A., \& Rubel, O. (2017). Beyond the opposition between altruism and self-interest: Reciprocal giving in reward-based crowdfunding. Journal of Business Ethics. https://doi.org/10.1007/s10551-017-3652-x.

Baumeister, R. F., \& Leary, M. R. (1995). The need to belong: desire for interpersonal attachments as a fundamental human motivation. Psychological Bulletin. https://doi.org/10.1037 /0033-2909.117.3.497.

Baumol, W. J., \& Bowen, W. G. (1993). Performing arts-the economic dilemma: a study of problems common to theater, opera, music and dance. Aldershot: Gregg Revivals. 
Belleflamme, P., Lambert, T., \& Schwienbacher, A. (2014). Crowdfunding: tapping the right crowd. Journal of Business Venturing. https://doi.org/10.1016/j. jbusvent.2013.07.003.

Blaseg, D., Schulze, C., \& Skiera, B. (2020). Consumer protection on Kickstarter. Marketing Science. https://doi.org/10.1287 /mksc.2019.1203.

Bretschneider, U., \& Leimeister, J. M. (2017). Not just an ego-trip: exploring backers' motivation for funding in incentive-based crowdfunding. The Journal of Strategic Information Systems. https://doi.org/10.1016/j.jsis.2017.02.002

Bürger, T., \& Volkmann, C. K. (2020). Mapping and thematic analysis of cultural entrepreneurship research. International Journal of Entrepreneurship and Small Business. https://doi. org/10.1504/IJESB.2020.107752.

Cameron, A. C., \& Trivedi, P. K. (2013). Regression analysis of count data. Cambridge, U.K.: Cambridge University Press.

Cassar, G. (2007). Money, money, money? A longitudinal investigation of entrepreneur career reasons, growth preferences and achieved growth. Entrepreneurship and Regional Development. https://doi.org/10.1080/08985620601002246.

Chan, C. R., \& Parhankangas, A. (2017). Crowdfunding innovative ideas: how incremental and radical innovativeness influence funding outcomes. Entrepreneurship Theory and Practice. https://doi.org/10.1111/etap.12268.

Cholakova, M., \& Clarysse, B. (2015). Does the possibility to make equity investments in crowdfunding projects crowd out reward-based investments? Entrepreneurship Theory and Practice. https://doi.org/10.1111/etap.12139.

Courtney, C., Dutta, S., \& Li, Y. (2017). Resolving information asymmetry: signaling, endorsement, and crowdfunding success. Entrepreneurship Theory and Practice. https://doi. org/10.1111/etap.12267.

Crosetto, P., \& Regner, T. (2018). It's never too late: funding dynamics and self pledges in reward-based crowdfunding. Research Policy. https://doi.org/10.1016/j. respol.2018.04.020.

Dacin, P. A., Dacin, M. T., \& Matear, M. (2010). Social entrepreneurship: why we don't need a new theory and how we move forward from here. Academy of Management Perspectives. https://doi.org/10.5465/amp.24.3.37.

De Charms, R. (2013). Personal causation: the internal affective determinants of behavior. London: Routledge.

Deci, E. L., Koestner, R., \& Ryan, R. M. (1999). A meta-analytic review of experiments examining the effects of extrinsic rewards on intrinsic motivation. Psychological Bulletin. https://doi.org/10.1037/0033-2909.125.6.627.

Deci, E. L., \& Ryan, R. M. (1985). Intrinsic motivation and selfdetermination in human behavior. New York: Plenum Press.

Galak, J., Small, D., \& Stephen, A. T. (2011). Microfinance decision making: a field study of prosocial lending. Journal of Marketing Research. https://doi.org/10.1509/jmkr.48. SPL.S130.

Gerber, E.M., Hui, J.S., \& Kuo, P.Y. (2012). Crowdfunding: why people are motivated to post and fund projects on crowdfunding platforms. In Proceedings of the International Workshop on Design, Influence, and Social Technologies: Techniques, Impacts and Ethics.

Goethner, M., Luettig, S., \& Regner, T. (2020). Crowdinvesting in entrepreneurial projects: disentangling patterns of investor behavior. Small Business Economics. https://doi. org/10.1007/s11187-020-00332-0.

Josefy, M., Dean, T. J., Albert, L. S., \& Fitza, M. A. (2017). The role of community in crowdfunding success: evidence on cultural attributes in funding campaigns to "Save the local theater.". Entrepreneurship Theory and Practice. https://doi. org/10.1111/etap.12263.

Kleinert, S., \& Volkmann, C. (2019). Equity crowdfunding and the role of investor discussion boards. Venture Capital. https://doi.org/10.1080/13691066.2019.1569853.

Kleinert, S., Volkmann, C., \& Grünhagen, M. (2020). Third-party signals in equity crowdfunding: the role of prior financing. Small Business Economics. https://doi.org/10.1007/s11187018-0125-2.

Konrad, E. D. (2018). Entrepreneurial behavior and financing structures in the German creative industries. In E. Innerhofer, H. Pechlaner, \& E. Borin (Eds.), Entrepreneurship in culture and creative industries (pp. 25-43). Springer: Cham.

Kuppuswamy, V., \& Bayus, B. L. (2017). Does my contribution to your crowdfunding project matter? Journal of Business Venturing. https://doi.org/10.1016/j.jbusvent.2016.10.004.

Lin, Y., Boh, W. F., \& Goh, K. H. (2014). How different are crowdfunders? Examining archetypes of crowdfunders and their choice of projects. Academy of Management Proceedings. https://doi.org/10.5465/ambpp.2014.209.

Lounsbury, M., \& Glynn, M. A. (2001). Cultural entrepreneurship: Stories, legitimacy, and the acquisition of resources. Strategic Management Journal. https://doi.org/10.1002 /smj. 188.

Mollick, E. (2014). The dynamics of crowdfunding: an exploratory study. Journal of Business Venturing. https://doi. org/10.1016/j.jbusvent.2013.06.005.

Moss, T. W., Neubaum, D. O., \& Meyskens, M. (2015). The effect of virtuous and entrepreneurial orientations on microfinance lending and repayment: a signaling theory perspective. Entrepreneurship Theory and Practice. https://doi. org/10.1111/etap.12110.

Moss, T. W., Renko, M., Block, E. S., \& Meyskens, M. (2018). Funding the story of hybrid ventures: crowdfunder lending preferences and linguistic hybridity. Journal of Business Venturing. https://doi.org/10.1016/j.jbusvent.2017.12.004.

Murray, A., Kotha, S., \& Fisher, G. (2020). Community-based resource mobilization: how entrepreneurs acquire resources from distributed non-professionals via crowdfunding. Organization Science. https://doi.org/10.1287 /orsc.2019.1339.

Nielsen, K. R., \& Binder, J. K. (2020). I am what I pledge: the importance of value alignment for mobilizing backers in reward-based crowdfunding. Entrepreneurship Theory and Practice. https://doi.org/10.1177/1042258720929888.

Parhankangas, A., \& Renko, M. (2017). Linguistic style and crowdfunding success among social and commercial entrepreneurs. Journal of Business Venturing. https://doi. org/10.1016/j.jbusvent.2016.11.001.

Ryan, R. M., \& Deci, E. L. (2000a). Intrinsic and extrinsic motivations: Classic definitions and new directions. Contemporary Educational Psychology. https://doi. org/10.1006/ceps.1999.1020.

Ryan, R. M., \& Deci, E. L. (2000b). Self-determination theory and the facilitation of intrinsic motivation, social development, 
and well-being. American Psychologist. https://doi. org/10.1037/0003-066X.55.1.68.

Ryan, R. M., \& Deci, E. L. (2017). Self-determination theory: basic psychological needs in motivation, development, and wellness. New York: Guilford Publications.

Sheth, J. N., Newman, B. I., \& Gross, B. L. (1991). Why we buy what we buy: a theory of consumption values. Journal of Business Research. https://doi.org/10.1016/0148-2963(91 )90050-8.

Stevenson, R. M., Kuratko, D. F., \& Eutsler, J. (2019). Unleashing main street entrepreneurship: crowdfunding, venture capital, and the democratization of new venture investments. Small Business Economics. https://doi.org/10.1007/s11187-0180097-2.

Sweeney, J. C., \& Soutar, G. N. (2001). Consumer perceived value: the development of a multiple item scale. Journal of Retailing. https://doi.org/10.1016/S0022-4359(01)00041-0.

Throsby, D. (1994). The production and consumption of the arts: a view of cultural economics. Journal of Economic Literature, 32(1), 1-29.

Throsby, D. (2008). The concentric circles model of the cultural industries. Cultural Trends. https://doi.org/10.1080 /09548960802361951.
Thürridl, C., \& Kamleitner, B. (2016). What goes around comes around? Rewards as strategic assets in crowdfunding. California Management Review. https://doi.org/10.1525 /cmr.2016.58.2.88.

Vansteenkiste, M., Niemiec, C. P., \& Soenens, B. (2010). The development of the five mini-theories of self-determination theory: an historical overview, emerging trends, and future directions. Advances in Motivation and Achievement. https://doi.org/10.1108/S0749-7423(2010)000016A007.

White, R. W. (1959). Motivation reconsidered: the concept of competence. Psychological Review. https://doi.org/10.1037 /h0040934.

Woronkowicz, J., \& Noonan, D. S. (2019). Who goes freelance? The determinants of self-employment for artists. Entrepreneurship Theory and Practice. https://doi. org/10.1177/1042258717728067.

Publisher's note Springer Nature remains neutral with regard to jurisdictional claims in published maps and institutional affiliations. 